Artículos

\title{
Relación del aparcamiento y la congestión vehicular en el Centro Histórico de Cusco.
}

\section{Relationship of parking and vehicular congestion in the Historico Center of Cusco}

\author{
Vargas Febres*, Carlos Guillermo; Serna Cuba **, Marco Antonio
}

\author{
Carlos Guillermo Vargas Febres* \\ cvargasf@uandina.edu.pe \\ Escuela Profesional de arquitectura de la Universidad \\ Andina de Cusco, Perú
Marco Antonio Serna Cuba **
mserna@uandina.edu.pe
Escuela Profesional de arquitectura de la Universidad
Andina de Cusco, Perú

\section{Estudios del Hábitat}

Universidad Nacional de La Plata, Argentina

ISSN: 2422-6483

Periodicidad: Semestral

vol. 18 , núm. 2,2020

aefau@fau.unlp.edu.ar

Recepción: 22 Enero 2020

Aprobación: 17 Diciembre 2020

Publicación: 30 Diciembre 2020

URL: http://portal.amelica.org/ameli/

jatsRepo/158/1581621008/index.html

\section{c) (i) $\odot$}

Esta obra está bajo una Licencia Creative Commons AtribuciónNoComercial-SinDerivar 4.0 Internacional. estudios del habitat $\mid$ FAU $=$
Resumen: El objetivo fue, inferir el grado relación de la oferta de estacionamientos con la congestión vehicular en el Centro Histórico de Cusco, desde un enfoque mixto; cuantitativo (conteo vehicular, registro de inventario de aparcamiento) y cualitativo, a través de entrevistas y cuestionarios a los usuarios. Para el diseño metodológico, se aplicaron instrumentos como fichas de registro para establecer la estadística descriptiva y relacional a través de la prueba de $\mathrm{r}$ de Pearson, así como la categorización e interpretación de entrevistas realizadas a los conductores y personas que tienen como origen y destino al Centro Histórico de Cusco. De los resultados encontrados, se desprende que la oferta supera a la demanda de estacionamientos, y esto debido a que la principal motivación de dirigirse al centro histórico es por motivos laborales siendo más del $42 \%$; además, se estableció que el tráfico vehicular en las calles aledañas a los polos de atracción supera el límite que pueden soportar sus vías. Finalmente, del análisis de relación, se encontró que existe relación significativa entre la oferta de estacionamientos y el tráfico vehicular en el centro histórico de Cusco.

Palabras clave: estacionamiento, tráfico, Centro Histórico Cusco, vehículo.

Abstract: The objective was to infer the degree of relationship between the supply of parking spaces and traffic congestion in the Historic Center of Cusco, from a mixed approach; quantitative (vehicle count, parking inventory record) and qualitative, through user interviews and questionnaires. For the methodological design, instruments such as registration cards were applied to establish descriptive and relational statistics through the Pearson r test, as well as the categorization and interpretation of interviews with drivers and people whose origin and destination were Historic Center of Cusco. From the results found, it appears that the supply exceeds the demand for parking lots, and this because the main motivation to go to the historic center is for work reasons, being more than $42 \%$; Furthermore, it was established that vehicular traffic in the streets surrounding the attraction poles exceeds the limit that their roads can withstand. Finally, from the relationship analysis, it was found that there is a significant relationship between the supply of parking and vehicular traffic in the historic center of Cusco. 
Keywords: parking, traffic, Historico Center Cusco, vehicle.

\section{INTRODUCCIÖN}

El presente trabajo, se estudian la problemática de la movilidad en el centro histórico de Cusco, tomando en cuenta la interrelación de variables poco estudiadas, como son el aparcamiento y el tráfico vehicular, entendiendo a éstas, como parte de un problema mucho mayor y que los resultados del estudio, ayudaran a comprender de mejor manera la problemática general que viene sufriendo el casco monumental de la ciudad del Cusco.

A pesar de existir países como Alemania u Suiza, que cuentan con ciudades patrimoniales donde lograron integrar sistemas de trasporte masivo como buses y trenes al interior de sus centros históricos, o ciudades como Estocolmo y Londres, donde las políticas para disminuir la presencia de automóviles en dichos centros, también existen centros históricos como el de la ciudad de Cusco, donde el creciente parque automotor y sumado al elevado número de viajes que tienen como origen y destino a su centro histórico, han provocado un alto nivel de congestión vehicular.

Ciudades como Zúrich, con más de un millón novecientos mil habitantes es uno de los mejores ejemplos de solución de transporte del y hacia su centro histórico, ya que más del $75 \%$ de estos viajes se realizan mediante sistema de transporte multimodal, contando con 02 decenas de líneas de tren, más de una decena de líneas de tranvía, y buses a diésel e incluso un teleférico. Es claro que su éxito se debe a la concentración de una sola autoridad del transporte y que éste esencialmente no se encuentre en manos del sector privado.Urbes exitosas intermedias en Latinoamérica, que cuenten con centros históricos y que a la fecha muestren experiencias exitosas de transporte a su centro histórico es la ciudad de Cuenca en Ecuador, con un poco más de medio millón de habitantes; cifra parecida a la población de Cusco que cuenta con cerca de medio millón de habitantes; posee con un sistema troncal de tranvía junto con buses que se adaptan a las secciones de las pequeñas calles históricas.

Sin embargo, desde hace ya más de 15 años, el centro histórico de Cusco, viene sufriendo los estragos del crecimiento del parque automotor, así como la eterna concentración de polos de atracción que no terminan de descentralizar el casco monumental y es ahí donde radica la valía del presente estudio.

\section{Centro Histórico de Cusco}

La conformación del Centro Histórico de Cusco obedece a una evolución urbana de la época Inca, su paso por la colonia, la república hasta nuestra actualidad. El núcleo central se establece a través de la plaza pública o (Huacaypata) posteriormente denominada plaza de armas o plaza mayor en nuestros días. Alrededor de ésta se ubicaron la mayor cantidad de nodos e hitos urbanos en sus diferentes épocas. 


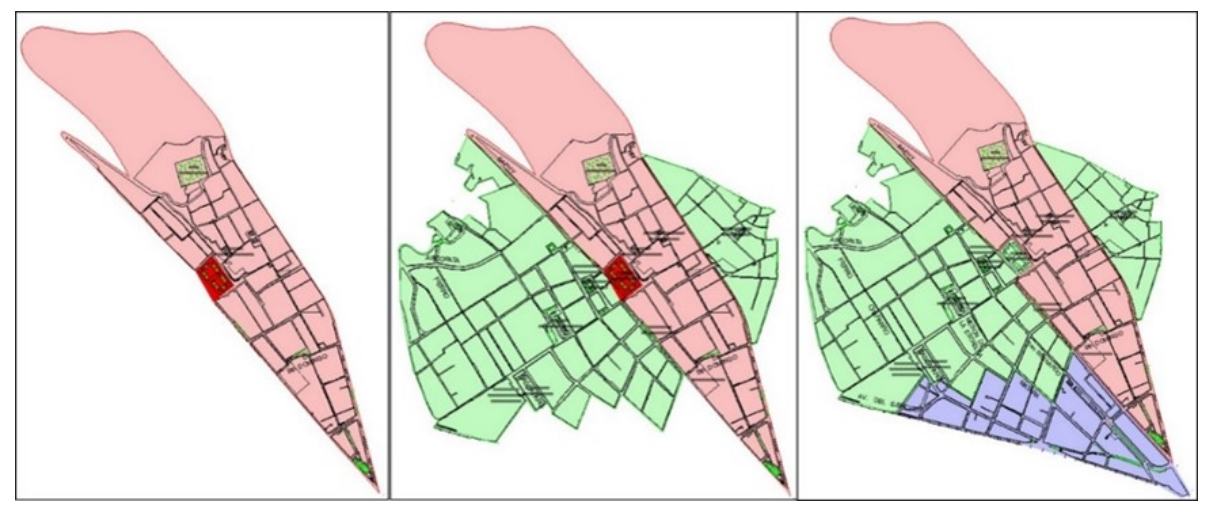

FIGURA 1

Evolución del Centro Histórico del Cusco.

Fuente: Sintetizado del Plan de Desarrollo Urbano. Municipalidad Provincial del Cusco.

La configuración de la morfología vial de la ciudad, demanda una organización centralizada donde los orígenes o destinos son el centro histórico de Cusco.

Los diferentes polos de atracción en la ciudad, se concentran dentro y alrededor del casco monumental del centro histórico de manera no estructurada y no planificada; provocando macro polaridades en los orígenes y destinos más frecuentes; con traslados de más de $10 \mathrm{Km}$ en muchos casos; esto adicionado a la estrechez de calles que impiden medios masivos de transporte público o privados, con lo que dichos traslados se deben realizar con vehículos particulares o servicios de taxi que a su vez provocan altos niveles de tráfico vehicular al interior del centro histórico cusqueño.

Polos Financieros: El edificio del Banco de la Nación, construido en 1966, que, a pesar de contar con sucursales en diferentes puntos de la ciudad, esta sede concentra el 70\% de actividades y transacciones de la Región; Banco de crédito del Perú; ubicado a una cuadra de la Plaza de Armas de la ciudad. El Banco Interbanck: construido en la segunda cuadra de la Avenida el Sol, Banco Continental, aledaño al Banco Interbanck y el Banco ScotiaBanck. Además, se ubican a lo largo de la avenida El Sol, entidades financieras como Cooperativas, Cajas Municipales y oficinas de las diferentes Agencias Financieras de Pensiones.

Polos Administrativos Públicos: Así la sede del Palacio de Justicia edificado a mediados de 1952, que concentra el 85\% de las actividades judiciales en la Región Cusco, la Municipalidad Provincial del Cusco, también llamado Plaza del Cabildo, cuya edificación fue construida en 1569 y adecuada periódicamente para el funcionamiento municipal,

Polos de Servicios: Oficinas de la Empresa prestadora de Servicios SEDA Cusco, ubicada en la plaza San Francisco a tres cuadras de la Plaza de Armas cusqueña, que concentra el $90 \%$ de actividades referidas a la dotación de agua y desagüe para toda la provincia; Telefónica, empresa privada destinada a la servicio de telefonía fija y móvil, ubicada en la cuarta cuadra de la Avenida el Sol y que pese a contar con puntos de venta a nivel de la región, es la única edificación en donde se concentran los trámites de nuevas líneas y áreas de reclamos. Del mismo modo otros operadores telefónicos como "Claro", "Entel" y Bitel" se ubican en edificaciones cercanas y al interior del Centro histórico. Adicionalmente, al ser el Cusco una ciudad Patrimonial, alrededor de las calles del casco monumental, se asientan más del 78\% de hoteles y alrededor de 1000 agencias de turísticas que brindan servicios a diferentes escalas. 


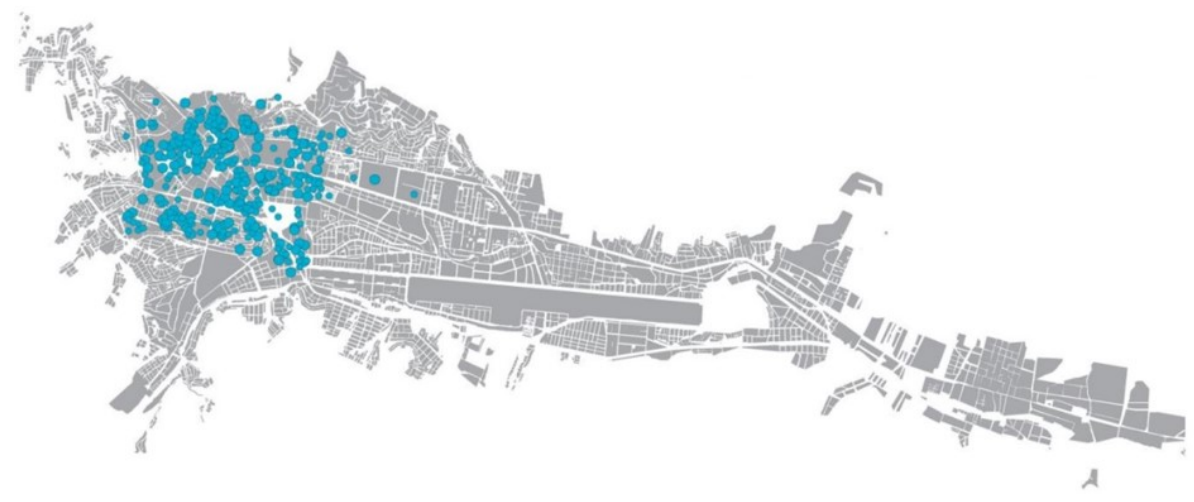

FIGURA 2

Polos de atracción de la ciudad de Cusco

Fuente: Extraído de Municipalidad Provincial del Cusco 2015

El estudio elaborado por la Corporación de Ingenieros del Transporte, arrojo que para el 2012, la capacidad máxima de transporte público en el centro histórico de Cusco debía ser de 1000 unidades, sin embargo, a la fecha se registran más de 5000 vehículos dentro de los cuales no se consideran a medios de transporte privados, taxis y carga.

El actual centro histórico, al igual que muchas ciudades patrimoniales, se conforma por la superposición, transformación y evolución urbana, según sus hechos históricos, culturas y economías preponderantes en cada espacio tiempo. Así, el núcleo urbano cusqueño, nace con el establecimiento de la cultura Inca, quienes establecen en la actual plaza de armas, el espacio público por excelencia denominado Huaycaypata y alrededor de esta, se planificaron los espacios religiosos y residencias de los diferentes monarcas incas. Desde ya, este sector de la ciudad concentraba funciones de las que se tenía origen del camino inca (Qhapaq ñan) declarado patrimonio de la humanidad; dichos caminos establecieron los cuatro ejes urbanos que hasta hoy siguen vigentes. Dichos ejes lo conformaban, hacia el sur este hacia el Collasuyo, mediante la rivera del rio Saphy, actual Avenida el Sol; al noreste hacia el Antisuyo, por Calle Hatunrumiyoc donde se ubica la piedra de los doce ángulos, hacia el noroeste, por la calle Saphy que también linda con la ribera del río del mismo nombre y hacia el suroeste, la conformación del espacio urbano del Cusipata, actual plaza Regocijo que comunicaba al Contisuyo. 


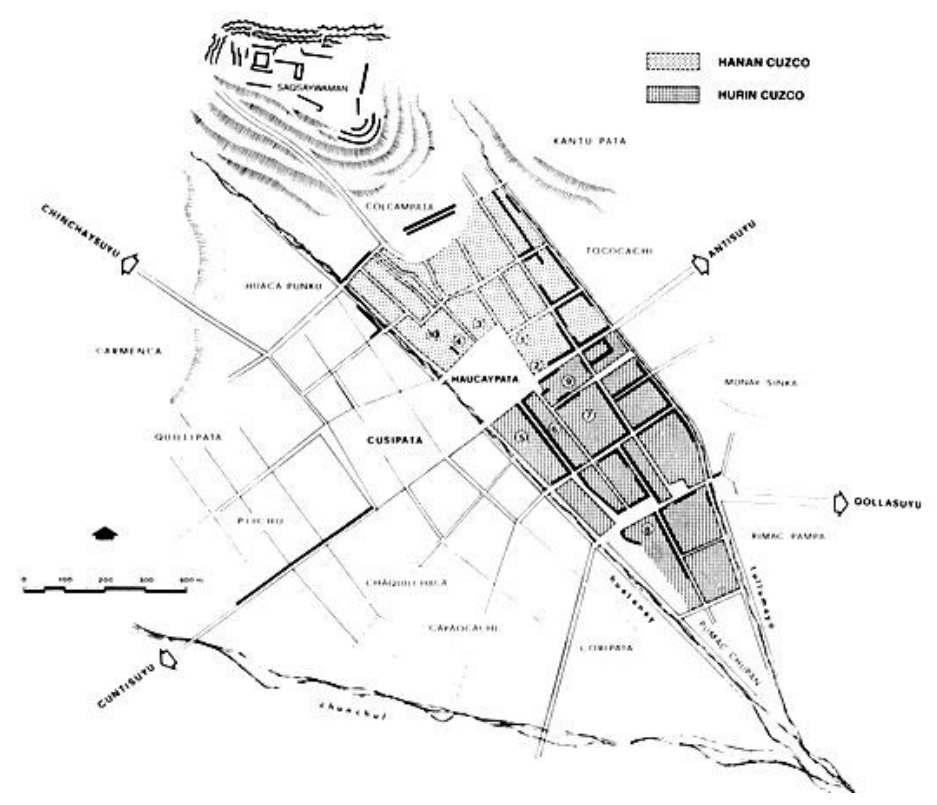

FIGURA 3

Plano del Centro Histórico de Cusco en la Época Inca.

Fuente: Extraído de Composición Urbana 2016.

Con la llegada de los españoles, y mediante normas como la Real Cédula de Felipe II, la extirpación de idolatrías, el terremoto de 1650 y la llegada del Obispo Mollinedo en 1673, se impuso una trama urbana tipo damero, en la que se respetaron los ejes urbanos incas utilizando los muros originales como cimiento o límites de las manzanas coloniales. Así la plaza colonial, estuvo conformada por infraestructura religiosa como la Basílica Catedral del Cusco y la Iglesia de la Compañía de Jesús, como muestra del auge y poderío que la orden de los Jesuitas llegó a tener en el nuevo Perú. Adicionalmente se establecieron siempre ubicadas alrededor de plazas, las edificaciones edilicias, como el Cabildo, ubicado en la plaza del Cabildo (actual Plaza de Regocijo) y otras expresiones religiosas como la iglesia de san Francisco asentada en la plaza del mismo nombre.

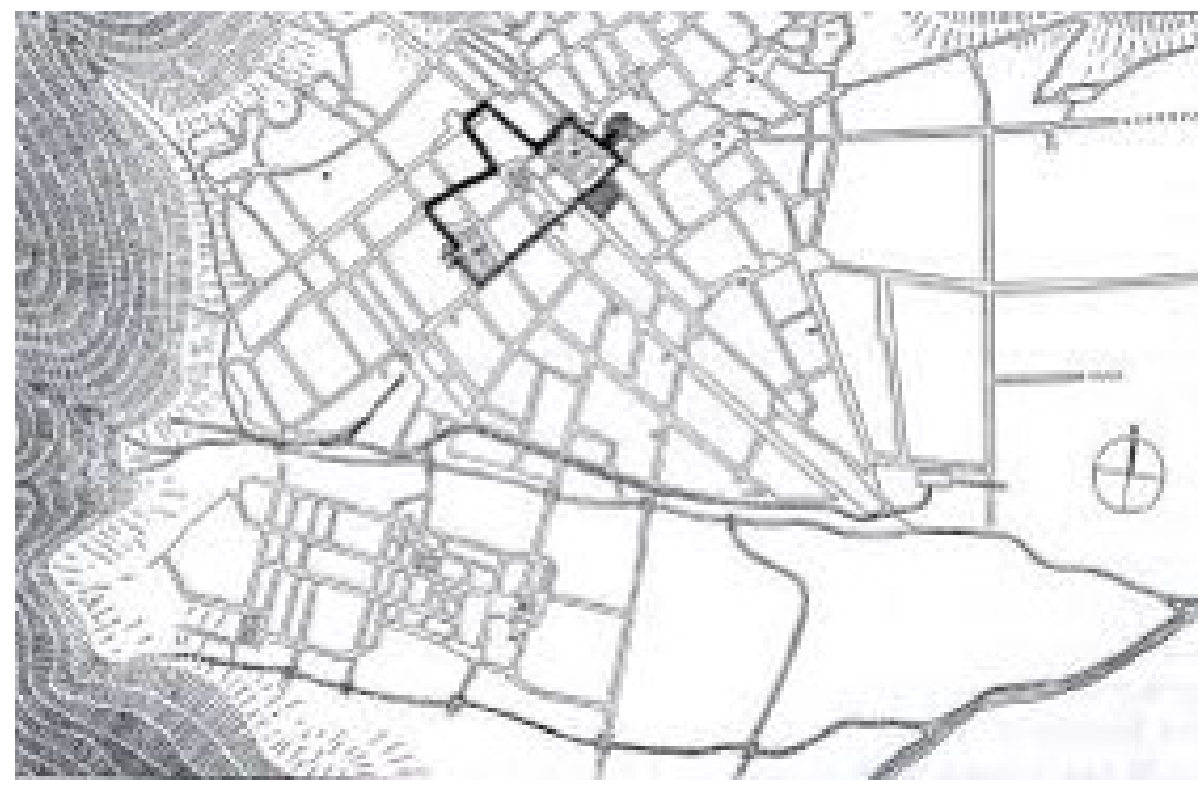

FIGURA 4

Cusco colonial 1746 según Esquivel y Navia, Tomo II pag. 341.

Fuente: Extraído de Viñuales, Graciela (2001). 
Ya a mediados del siglo XX el crecimiento urbano del Cusco, mantuvo como núcleo político, económico y urbano al actual centro histórico; los bordes de la ciudad comenzaron a expandirse con dirección al sur de la ciudad, con el establecimiento de la tricentenaria Universidad Nacional de san Antonio Abad del Cusco, ubicada en la recién planificada Avenida de la Cultura que años después se conformará como el principal eje urbano y de transporte de la ciudad. Se conforman dos ejes procesionales, que en sus extremos tenían a la Cuesta San Blas con la calle Hatunrrumiyoc pasando por la Plaza de Armas con las iglesias de la Catedral y la Compañía de Jesús; finalizando en la Plaza San Francisco y la calle santa Clara. Finalmente, luego del terremoto de 1950 donde más del 50\% de la infraestructura del Centro histórico sufrió dalos considerables, se plantea el Plan Kubler de 1951, donde se apertura nuevas calles, se dividen predios y conventos para dar paso a vías pensadas en el vehículo como principal medio de transporte de la época; sin embargo, las secciones de vías, la falta de planificación de espacios de estacionamiento y sumado al creciente parque automotor en la década de los 90 y 2000, provocaron el tráfico vehicular que actualmente observamos. De otro lado, mucho más visible a partir de la década del 70, la Avenida El Sol, toma mayor protagonismo por eventos religiosos, festejos estudiantiles, marchas cívicas y militares, protestas de la población, así como ser considerado como el mayor eje comercial de la ciudad en donde se ubican la mayor cantidad de entidades financieras, políticas, judiciales, comercio, servicios turísticos, etc.

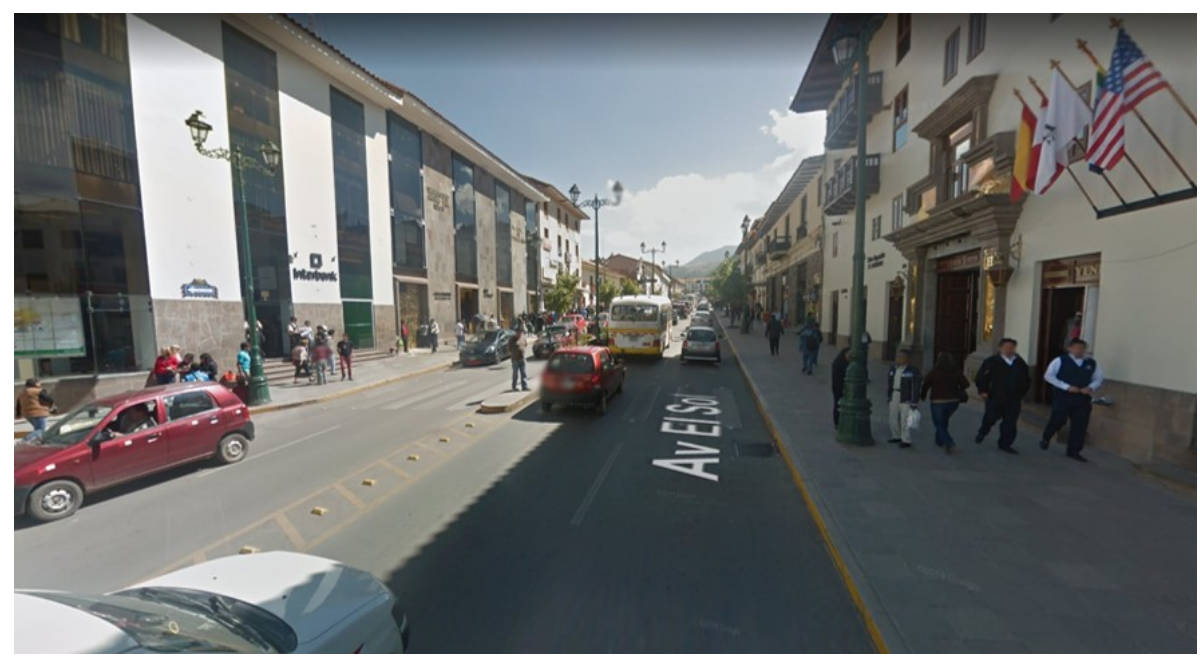

FIGURA 5

Vista de la Avenida el Sol.

Fuente: Extraído de Googel maps 2020).

\section{Movilidad en Centros Históricos}

Según el Plan de Movilidad y Espacio Público del Cusco (2016) establece que la afluencia al centro histórico es predominante frente a las demás macro zonas de la ciudad, siendo los modos de transporte como sigue: $50 \%$ de manera peatonal, $35 \%$ en transporte público, $9 \%$ en taxi, 3\% de manera particular y $3 \%$ en movilidad escolar; siendo el número de viajes alrededor de 117,648 mediante todos los tipos de transporte. Además, expone que el $40 \%$ de los viajes se deben a trabajo, el $26 \%$ por motivos de estudio, el $20 \%$ por ocio y el $14 \%$ por compras; evidenciando así que los polos de atracción predominantes son las edificaciones que albergan instituciones o empresas del sector laboral.

Los planes de infraestructura de redes viales, en el tiempo fueron enfocados en base a metodologías de la oferta y la demanda, por lo que, a mayor cantidad de viajes al centro histórico, tuvo que crecer la oferta de estacionamientos, destinado áreas públicas, restringiendo vías para poder equilibrar la creciente demanda. 
Debido a la concentración de actividades en el Centro Histórico es que también las autoridades del transporte en Cusco, establecieron las Redes Colectoras orientadas al traslado de personas en dirección del casco monumental, provocando con ello la aglomeración o incremento de unidades de transporte público que consecuentemente determina el crecimiento del tráfico vehicular en la zona de estudio.

Por ello el sistema de aparcamiento en el centro histórico está determina por zonas de parqueo mas no por número aparcamientos, con lo cual la búsqueda de un espacio para estacionar obliga a los conductores a recorrer mayores distancias y circular mayores tiempos hasta encontrar un espacio.

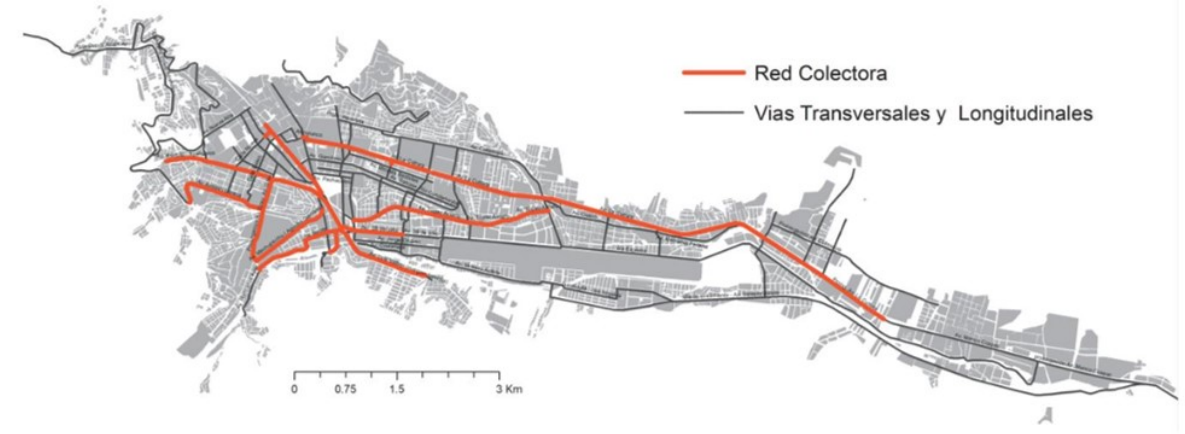

FIGURA 6

Red colectora y vías trasversales y longitudinales de transporte. Fuente: Extraído de Municipalidad Provincial del Cusco 2015

Del levantamiento de campo en la presente investigación se desprende que el $64.86 \%$ de vehículos aparcados se debe a actividades laborales, mientras que el 13.74\% los realiza por trámites administrativos ante entidades públicas y privadas y el $9.28 \%$ debido a transacciones financiera. Además, se encontró que el 49\% de vehículos aparcados, corresponde a tipología de autos, el 28\% camionetas, 5\% camiones de carga y $5 \%$ a motocicletas.

Según el Censo del 2017, en el distrito de Cusco residen 396,118 personas, que representan el 30\% de la población provincial, además se desprende que 73,557 personas habitan en el centro histórico de Cusco representando el 19\% de la población provincial. Este flujo de población que deja de vivir en los inmuebles, se debe a la creciente demanda de locales orientados a servicios turísticos, ya que como se apuntó en párrafos anteriores, más del 90\% de hoteles y agencias de turismo se encuentran en el Centro Histórico, por lo que dicha demanda de espacio comercial, obliga a los propietarios a arrendar o vender sus viviendas a altos precios y trasladarse a zonas residenciales consolidadas o en proceso de consolidación.

En el centro histórico de Cusco, existe un conflicto de centralidades, entre la centralidad funcional determinado por los servicios, centros laborales y centro financiero y el centro histórico en sí mismo como núcleo urbano de la ciudad.

\section{Aparcamiento en el Centro Histórico}

El sistema de transporte en general se estructura por tres sectores que son la vía, el vehículo y el estacionamiento, siendo este último la representación del origen y destino de los viajes que pueden ser de propiedad privada o pública; el sistema de transporte presenta una relación directa entre el parque automotor y espacios idóneos de estacionamiento que deben estar ubicados de manera estratégica en la ciudad. (Carranza, Céspedes, \& Salgado, 2017).

Del mismo modo (Vicente M. , 1983), sostiene que debe existir un equilibrio entre el los medios de transporte, sean público y/o privados y los aparcamientos ya que entre ellos existe una estrecha relación de 
convivencia determinada por el uso de suelo y la estructura vial de la ciudad. Por tanto, la relación entre la masa de vehículos, repercutirá directamente en la cantidad d estacionamientos necesarios en la ciudad.

Según (Arce, 2008), clasifica a los estacionamientos en dos grupos siendo: a) En playas privadas por horas, si bien es cierto en el caso cusqueño, no cumplen con la normatividad vigente registrándose 14 playas privadas acondicionadas en lotes baldíos con construcciones precarias e instalaciones tipo caramanchel (rollizos y calamina galvanizada) que cubren a los vehículos, pisos de tierra; y b) En vías públicas (calles), localizados en sectores permitidos y no permitidos, registrando estacionamientos formales temporales para el sector turismo.
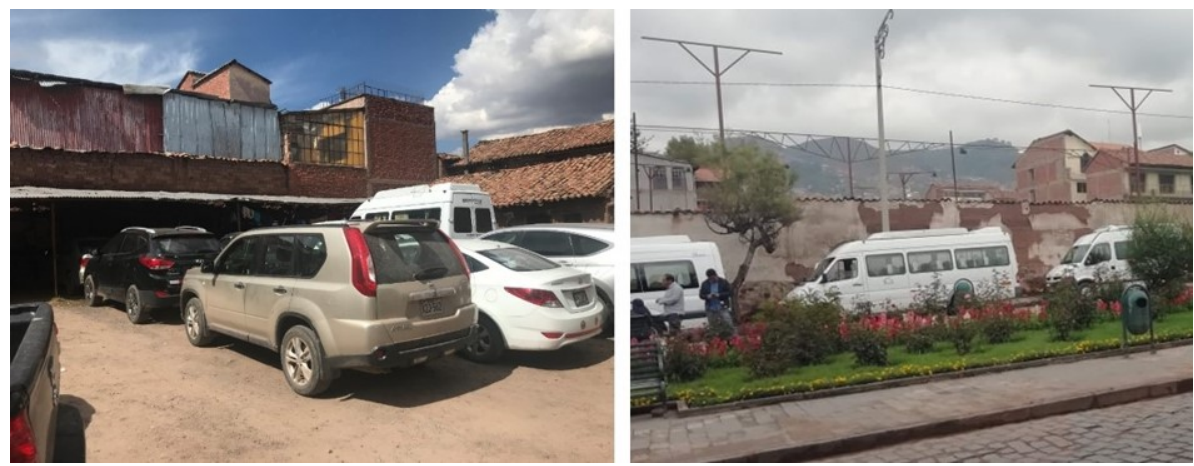

FIGURA 7

Cocheras en playas privadas y en vías públicas del Cusco.

Fuente: Elaboración propia.

Dentro de la clasificación de estacionamientos en la vía pública, tenemos una subdivisión donde se encuentra tres tipos de estacionamiento; así existen los gratuitos o bajo un costo por hora, los estacionamientos con exclusividad que pertenece a estacionamientos para taxis, buses o espacios de carga y descarga y finalmente el estacionamiento no permitido que pese a estar prohibido, en la realidad lo ocupan vehículos en el día a día.

Si bien es cierto. Las autoridades municipales mediante Ordenanza Municipal 022-2016-MPC, prohíbe los estacionamientos en la vía pública en todo en Centro Histórico de Cusco, sumado al plan de peatonalización aprobado por Ordenanza Municipal 032-2013-MPC siendo esto una recomendación de UNESCO para Ciudades Patrimoniales; sin embargo, como se aprecia en la figura 04, los conductores no solo de vehículos particulares, sino principalmente del sector turismo, hacen caso omiso de las disposiciones municipales y estacionan sus vehículos en sitios prohibidos como son las vías públicas. Ya para el 2016, el Plan de Movilidad de la Ciudad del Cusco determino la existencia de un déficit de 2243 áreas de aparcamientos diarios al interior del Centro Histórico de Cusco. 

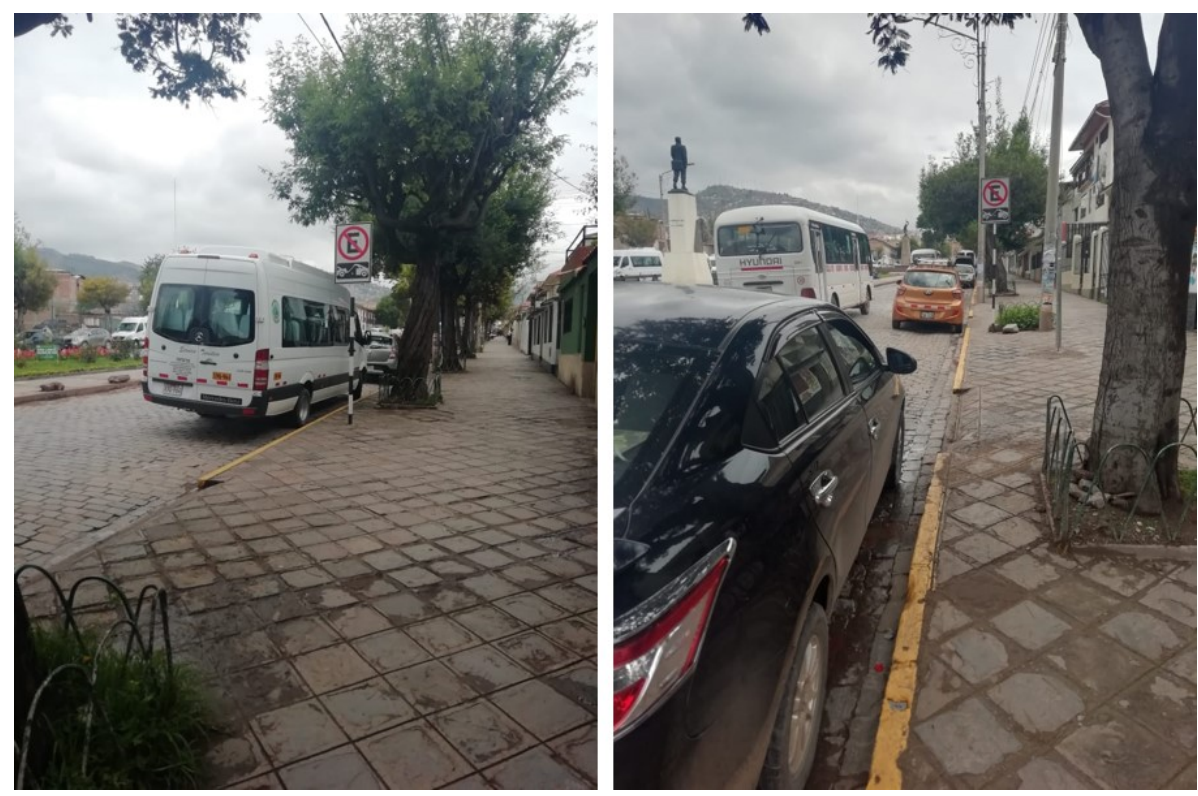

FIGURA 8

Aparcamiento en el Centro Histórico de Cusco

Elaboración Propia.

\section{Tráfico Vehicular en el Centro Histórico}

Hablar del termino tráfico o congestión vehicular nos referimos al concepto desarrollado por (Bull \& Thomson, 2002) quienes la definen como la demora en la circulación de vehículos; es decir, que se considera congestión si es que el tiempo en que un vehículo al ingresar a un flujo de tránsito incrementa el periodo de tiempo en el viaje de otros automóviles.

Para (Bull, Congestión de tránsito: el problema y cómo enfrentarlo., 2003), la congestión se produce cuando un vehículo no posee la libertad de desplazarse disminuyendo la velocidad e incrementando las demoras al libre flujo; por ende se desprende la hipótesis de que a mayor volumen de automóviles en una vía, declinan la velocidad de los mismos.

Para (Cordero, 2012), en los diferentes Centros Históricos se heredaron calles angostas debido a la trama colonial con lo cual se observa el creciente número de automóviles que circulan en sus calles, esto debido a la demanda de sus diferentes tipos de zonas y a la restringida cantidad y sección de vías que no pueden contener a tantos vehículos con el consecuente problema de tráfico vehicular.

Debido al plan piloto "Plaza para todos", en el cual se restringe el paso vehicular en las calles conformantes a la Plaza de Armas del Cusco, es que se redirección el flujo vehicular a calles en las que por su sección y orientación no soporta la cantidad de automóviles que circulan en busca de un estacionamiento.

La ciudad al haber crecido de manera longitudinal en dirección de oeste a este y al haberse concentrado los polos de atracción en el centro histórico de Cusco, es que la cantidad de viajes de origen y destino incrementa el flujo vehicular a este sector de la ciudad y tomando en cuenta las secciones de vía y la cantidad del parque automotor es que se observan colas de vehiculas en ciertos sectores del casco monumental, por lo que la hipótesis de nuestro estudio radica en que "El déficit de estacionamientos, se relaciona directamente con el tráfico vehicular en las calles de mayor impacto del Centro Histórico del Cusco".

La teoría del "flujo de tráfico" desarrollada por (Wardrop \& Wuitehead, 1952) plantea la aplicación de figuras matemáticas y estadística para comprender esta problemática, posteriormente se emplea modelos de dinámicas de fluidos (modelo LWR) citado por (Linauer \& Leihs, 2003). 


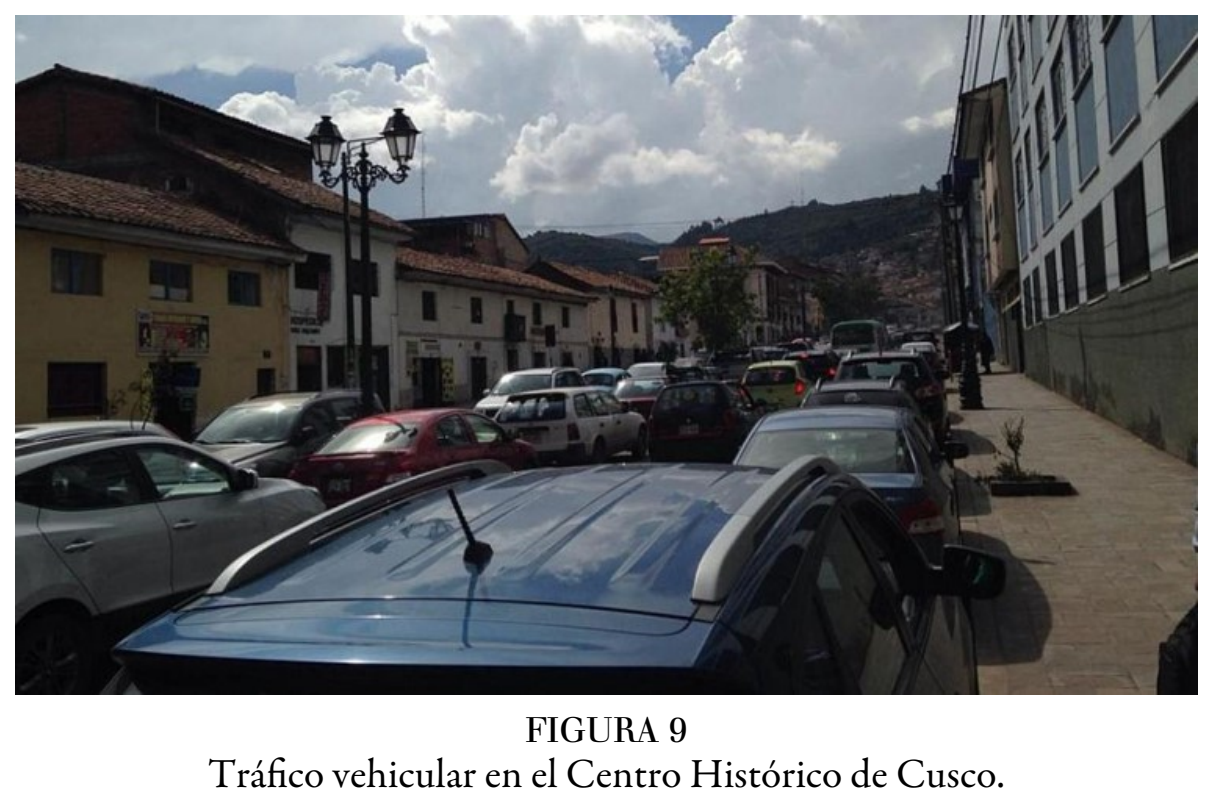

Existen investigaciones y estudios relacionados a cada variable de manera independiente, como Alfonso Sanz quien analiza el tráfico vehicular en centros urbanos encontrando como relación directa entre el tráfico vehicular con la prohibición del tránsito vehicular, es decir que el factor cultural de las personas influye directamente al momento de decidir aparcar en sitios prohibidos.

Para (Thomsom \& Bull, 2001) estudio el déficit de espacios de estacionamiento en zonas primarias de los centros históricos, se debe a la falta o mala planificación operativa por lo que el bajo nivel de satisfacción del usuario que busca un espacio de aparcamiento para realizar las actividades laborales y comerciales.

Por otro lado (Gehl \& Gemzoe, 2002), en su investigación denominada "Nuevos espacios urbanos" encuentran que existe relación significativa entre las playas de estacionamientos y el tráfico vehicular, siendo la relación, a más estacionamientos, menor tráfico vehicular.

Sin embargo el caso cusqueño posee una singular realidad, ya que a la fecha se propusieron e implementaron planes urbanos en los que se destinó playas de estacionamientos privados, espacios en las vías públicas y que por otro lado, ordenanzas municipales que buscan la peatonalización de plazas y calles al interior del centro histórico cusqueño, prohibiendo de sobre manera la posibilidad de estacionar los vehículos que tienen como destino el casco monumental; todas estas intervenciones, no terminan de solucionar la problemática del tráfico vehicular en el casco monumental.

Por ello la presente investigación no busca justificar los planes urbanos o las teorías de movilidad urbana en base a peatonalización del centro histórico, sino por el contrario evidenciar la realidad problemática existente, buscando encontrar la relación o no entre las variables de tráfico vehicular y espacios de estacionamiento en las calles del centro histórico de Cusco. Esto permitirá entender que las verdaderas razones de este fenómeno, no responde a soluciones físicas (Estacionamientos versus peatonalización), o planes de desarrollo urbano quinquenales que no hacen otra cosa que maquillar la realidad y no abordan el fondo de la problemática. Así demostramos que en calles donde existe espacios de estacionamiento, también existe tráfico vehicular y que además en calles donde no existe espacios de aparcamiento, los niveles de tráfico vehicular bajan sustancialmente, sin embargo no desaparecen.

\section{MATERIAL Y MÉtodos}

La investigación se desarrolló mediante un enfoque mixto, cuantitativo y cualitativo ya que se manejaron datos estadísticos mediante levantamiento de información numérica de cantidad, tipos, dimensiones, 
ubicación y recurrencia de estacionamientos, así como tiempos de retraso en intersecciones que ayudarán a medir el tráfico vehicular en las calles analizadas. Del mismo modo se aplicaron entrevistas a los conductores para establecer la motivación por la cual tienen como destino el centro histórico de Cusco, así como determinar las causas de la ocupación de estacionamientos en espacios expresamente prohibidos por la autoridad. Con lo cual la comprobación de la hipótesis se da a través del análisis correlacional $\mathrm{r}$ de Pearson y la categorización de respuestas, volcadas a un diagrama de manchas en el plano del casco monumental. El alcance del estudio es de nivel descriptivo relacional ya que se analizan las características de las variables, así como su grado de relación entre ellas.

El diseño investigativo es de enfoque no experimental debido a la falta de azahar en la asignación de grupos de análisis; la población de estudio estuvo determinada por los espacios de estacionamientos, los vehículos, los conductores y las personas que tiene como destino y origen el centro histórico de Cusco. Se optó por una muestra no probabilística accidental, ya que se aplicaron los instrumentos solo a las personas que eventualmente se encontraban en las calles analizadas, así como los vehículos que llegaban a los espacios de estacionamiento.

Por otro lado, la investigación fue de corte longitudinal ya que la aplicación de los instrumentos se realizó durante un periodo de treinta días consecutivos tomando en cuenta las horas punta y horario lento. La observación fue la técnica empleada en el estudio, basada en instrumentos como fichas de registro elaborada por los investigadores en base a los formatos de la HCM (2000) y validada estadísticamente con un alfa de Cronback con un P valor de 0.92 además de ser sometido a juicio de dos expertos en transitabilidad y movilidad urbana.

Se planteó el estudio para determinar el grado de relación entre la variable dependiente (Tráfico vehicular) y la variable independiente (estacionamientos); para ello se aplicó para el análisis cualitativo a través del software ATLAS para la categorización de resultados y el análisis cuantitativo, la prueba estadística de $\mathrm{r}$ de Pearson, mediante el software SPSS; los resultados se presentan a modo de gráficos de planos superpuestos en el análisis cualitativo que demuestra la superposición de eventos en diferentes calles del centro histórico; además se exponen mediante tablas de relaciones y diagramas de dispersión para la comprobación de la hipótesis alterna.

Entre las técnicas estadísticas aplicadas se empleó en la etapa descriptiva, análisis de frecuencias para determinar las características de ambas variables y para el enfoque cualitativo, la significancia mediante la categorización planimetría utilizando distinciones colorimétricas según el grado de relación, finalmente la etapa relacional la prueba de hipótesis $r$ de Pearson para determinar la relación entre variables. 
TABLA 1

Variables, dimensiones e indicadores

VARIABLE

$\begin{array}{ll}\text { 1. Batería } & \text { 2. Orientación } \\ \text { Estacionamiento Tipo de } & \text { estacionamiento } \\ & \text { 4. Longitud de la } \\ \text { batería } & \\ & \text { 5. Señalización } \\ \text { 6. Legalidad } & \\ \text { Tráfico Vehicular } & \begin{array}{l}\text { 1. Tipo de Transporte } \\ \text { 2. Tipo de vehículo } \\ \text { 4. Tiempo de } \\ \text { aparcamiento } \\ \text { 5. Retraso por } \\ \text { intersección }\end{array}\end{array}$

Número de estacionamientos

Sentido de la vía

En playa o vía pública

Largo y ancho de la batería

Existencia de la demarcación en la vía

Cantidad de estacionamiento permitidos

Servicio de transporte

Según capacidad de pasajeros

Actividad por la que acude al centro histórico

Cantidad de horas de aparcamiento

Tiempo de demora por intersección

Fuente: Elaboración propia. 


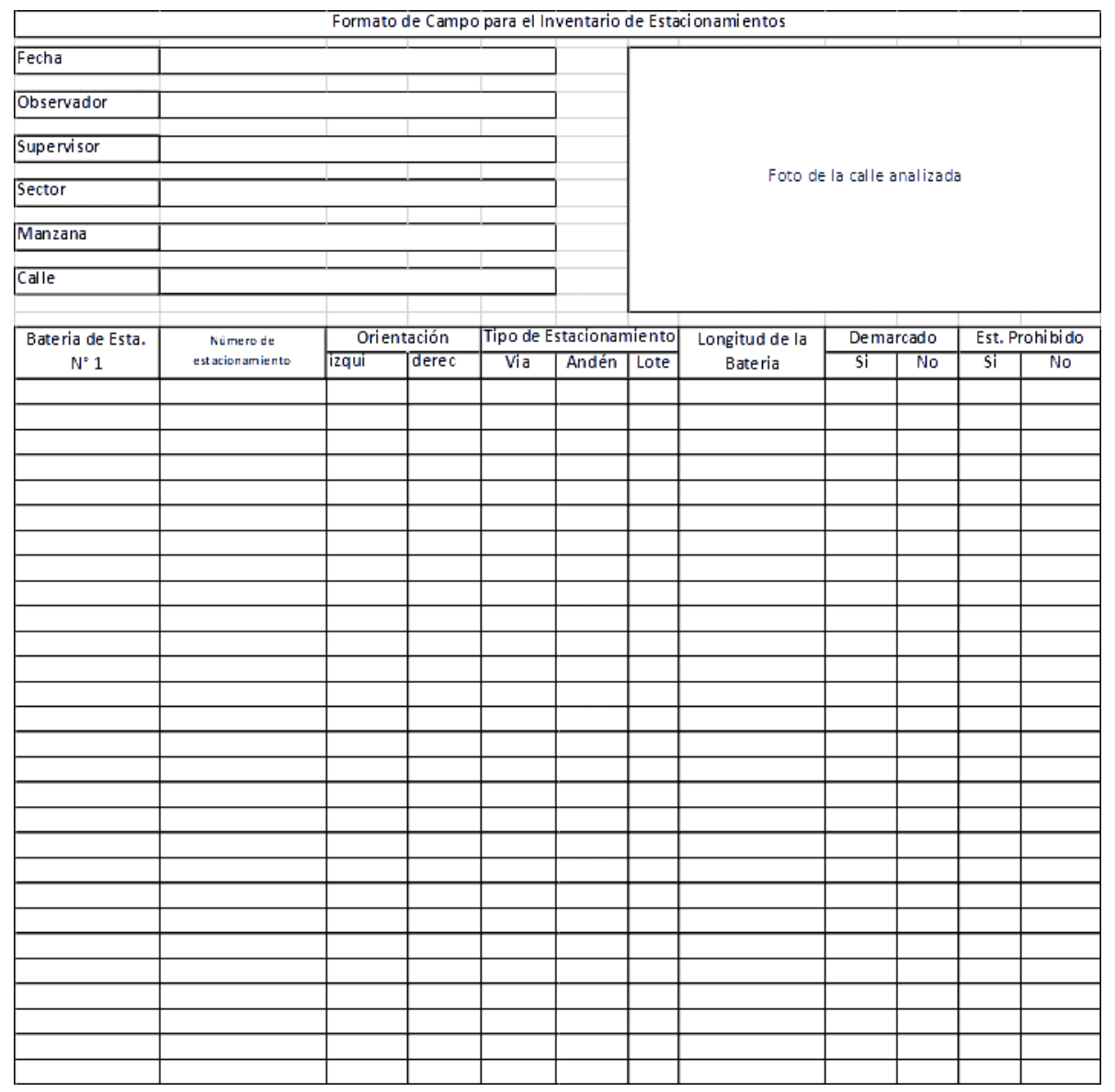

TABLA 2

Instrumento de registro de datos - Aparcamiento.

Fuente Elaboración propia.

La ficha de registro para la variable aparcamiento, permitió recolectar data por un periodo de 30 días considerando de lunes a domingo y desde ñas 6:30 am hasta la 8:00 pm de cada día, así se obtuvo tanto datos de las horas picos, así como de espacios de tiempo en la que la cantidad de vehículos promedia el estándar normal; por ello es que trabajamos con los ratios de promedio para establecer una media de información.

Además, dicha ficha permito establecer los datos descriptivos de la variable y así comprender de mejor manera las características de los vehículos, así como de los espacios de aparcamiento, sean o no permitidos para determinar la oferta real de espacios de aparcamiento y la frecuencia de uso de los mismos. Cabe mencionar como el enfoque metodológico es mixto, también se aplicó la entrevista semi estructurada para identificar las motivaciones por las que los conductores deciden estacionar en el centro histórico y bajo el conocimiento de la ilegalidad de ciertos espacios de aparcamiento. Esto nos permitió comprender las características socioculturales de la población de estudio. 
TABLA 3

Instrumento de registro de datos -Tráfico vehicular.

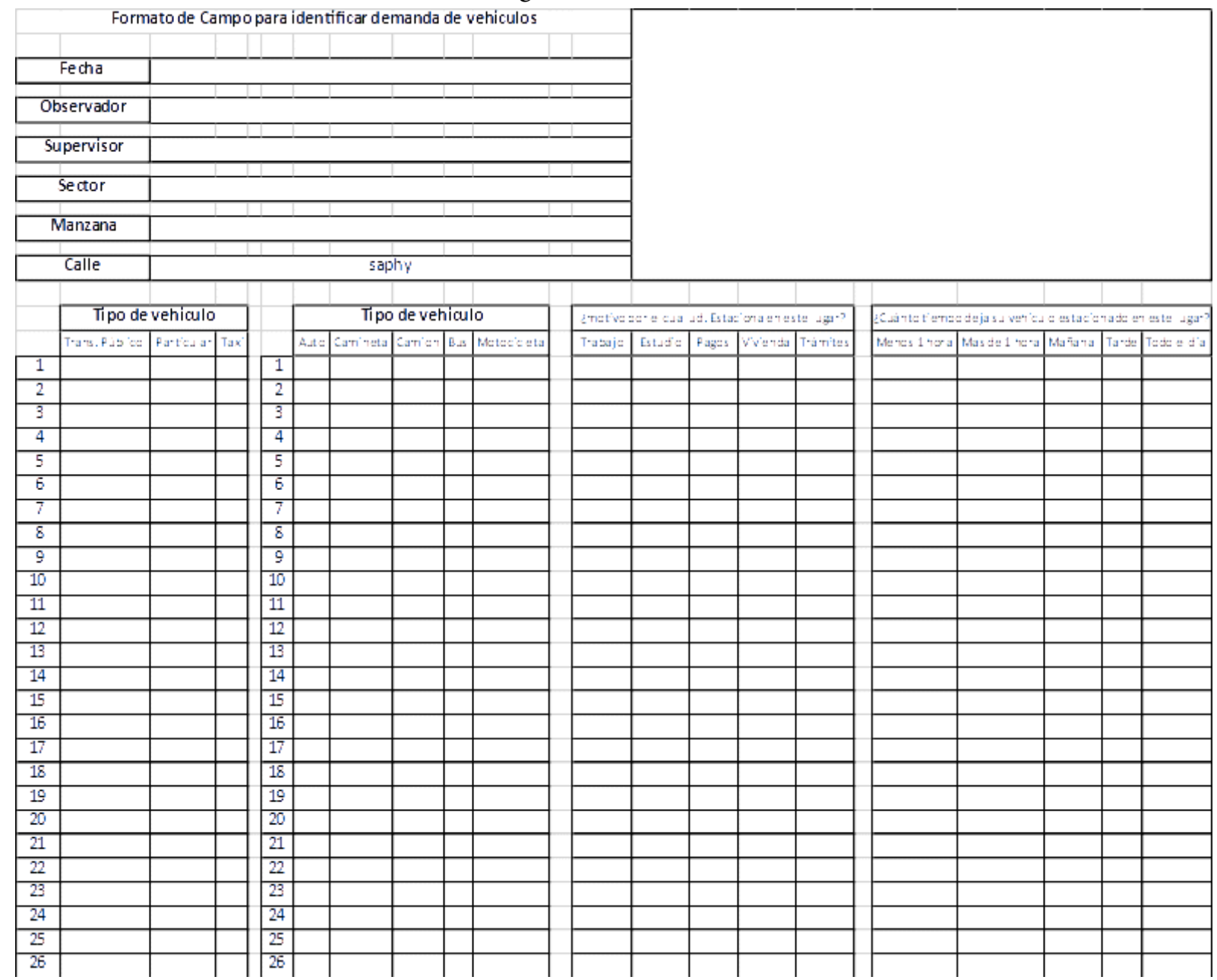

Fuente: elaboración propia

De igual forma, la ficha de registro para la variable de tráfico vehicular se aplicó el conteo vehicular, así como el registro de tiempo en el que los vehículos demoran su andar enfocados en las intersecciones de las calles analizadas, para ello la muestra fue aleatoria accidental, según el registro del observador; con ello se pudo medir el nivel de congestión vehicular y que al igual que la anterior variable, se trabajó con estadística descriptiva de frecuencias y medias por calles, para así poder interrelacionar ambas variables. 
TABLA 4

Instrumento de registro de datos - tiempos de retraso.

\begin{tabular}{|c|c|c|c|}
\hline Intersección & Demora Promedio & Óptimo & Nivel de Confianza \\
\hline Avenida Pardo- Av. Grau & 23.6 & 5.09 & $99 \%$ \\
\hline Avenida Pardo- Av. San Miguel & 8.4 & 3.56 & $99 \%$ \\
\hline Avenida Pardo- Av. Garcilaso & 37.8 & 11.52 & $99 \%$ \\
\hline Avenida Pardo- Av. El Sol & 24.3 & 9.56 & $99 \%$ \\
\hline Promedio & 23.53 & $\overline{7.43}$ & 0.99 \\
\hline Calle Heladeros - Calle Espaderos & 12 & 1.94 & $99 \%$ \\
\hline Calle Heladeros - Calle Garcil aso & 13.2 & 6.03 & $99 \%$ \\
\hline Calle Espinar-Calle Mantas & 29.3 & 10.73 & $99 \%$ \\
\hline Promedio & 18.17 & 6.23 & 0.99 \\
\hline Calle Matará - Calle Quera & 18.9 & 7.41 & $99 \%$ \\
\hline Calle Matará- Calle Belen & 37.8 & 16.92 & $99 \%$ \\
\hline Calle Matará- Calle Kijllu & 5 & 4.12 & $99 \%$ \\
\hline Calle Matará - Av. Grau & 37.3 & 11.52 & $99 \%$ \\
\hline Promedio & 24.75 & 9.99 & 0.99 \\
\hline Plaza Nazarenas - Calle Palacios & 24.3 & 9.58 & $99 \%$ \\
\hline Plaza Nazarenas - Cuesta del Almirante & 18.8 & 7.41 & $99 \%$ \\
\hline Promedio & 21.55 & 8.50 & 0.99 \\
\hline Calle Saphy-Calle Tecsecocha & 14.2 & 9.93 & $99 \%$ \\
\hline Calle Saphy - Tambo de Mone tro & 11.3 & 7.65 & $99 \%$ \\
\hline Promedio & 12.75 & 8.79 & 0.99 \\
\hline Plaza San Fransísco - Calle Santa Clara & 26.8 & 9.32 & $99 \%$ \\
\hline Plaza San Fransísco - Meson de la Es trela & 37.9 & 16.5 & $99 \%$ \\
\hline Plaza San Fransisco - Calle Garcilaso & 14.5 & 9.15 & $99 \%$ \\
\hline Plaza San Fransísco - Calle Granado & 13.5 & 1.82 & $99 \%$ \\
\hline Promedio & 23.18 & 9.20 & 0.99 \\
\hline Av. Tullumayo - Plaza Límaqpampa & 16.3 & 6.61 & $99 \%$ \\
\hline Av. Tullumayo - Calle Inticahuarina & 5 & 4.18 & $99 \%$ \\
\hline Av. Tullumayo - Av. Garcilaso & 26.2 & 9.17 & $99 \%$ \\
\hline Av. Tullumayo-Av. Pachacutec & 14.7 & 6.31 & $99 \%$ \\
\hline Av. Tullumayo- Av. El Sol & 12.3 & 1.35 & $99 \%$ \\
\hline Promedio & 14.90 & 5.52 & 0.99 \\
\hline
\end{tabular}

Fuente: elaboración propia.

\section{Resultados}

Como se sostuvo en la metodología, la presente investigación presenta los resultados en dos etapas correlativas, la primera destinada a datos descriptivos que evidencia el estado y características de las variables de estudio y en una segunda etapa se aplicó la contratación de la hipótesis general

\section{Aparcamiento}

1. Para entender la relación de las variables, inicialmente debemos determinar las características de cada una de ellas; así para la variable Aparcamiento (estacionamientos) se realizó el levantamiento de datos en un periodo de tiempo de un mes en la que se entrevistó y encuesto tanto a los conductores en el caso de vehículos particulares y a los ocupantes en base a los vehículos de trasporte público, así como taxis y vehículos de carga.

De la estadística descriptiva encontramos que los promedios de viajes al Centro Histórico más del a mitad de ellos los realizan por motivos laborales, es decir que el desplazamiento a este sector de la ciudad lo realizan en el intervalo de los horarios de oficina. Además, se percibió que 
las horas de mayor concurrencia fueron las 7:00 am y 1:00 pm, coincidiendo con los horarios de ingreso a los diferentes puestos de trabajo, así como la salida para la ingesta de alimentos. Sobre la tipología de trabajos se estructura en tres sectores predominantes: a) Instituciones Públicas políticas, como las oficinas de la Municipalidad Provincial del Cusco, la Superintendencia Nacional de Administración Tributaria (SUNAT), el Palacio Judicial entre otros; b) Entidades financieras, como bancos públicos y privados, cooperativas, cajas municipales, casas de cambio; c) Sector Turismo con más de 1000 agencias registradas con locales al interior del Centro Histórico así como locales comerciales destinados a la venta de artesanías y suvenires orientados a los turistas que visitan el eje procesional y las iglesias patrimoniales coloniales.

De la figura 06 también se desprende el creciente éxodo de propietarios de viviendas que con el tiempo migran a otros sectores de la ciudad reduciendo su ocupación en un $6.58 \%$. esto concuerda con el número de agencias y locales turísticos ubicados en casco monumental; es decir que la creciente demanda de locales y espacios destinados para el turismo, obliga a los propietarios y habitantes de viviendas a alquilar, vender o concesionar dichas viviendas que luego son adecuadas en locales comerciales que brindan servicios turísticos como restaurantes, agencias de turismo, hospedajes, tiendas de tatuajes y comercio en general.

Otro de los indicadores con mayor relevancia en la investigación está determinado por el tiempo de ocupación de los espacios de estacionamientos que nos da mayores luces de la movilidad vehicular en las calles donde existe dichos espacios de aparcamiento. Así se puede observar que más del $60 \%$ de ocupaciones se realizan por periodos de tiempo de ocho a más horas, esto quiere decir que este grupo de personas concurre a estos espacios a inicios de la jornada laboral (7.00 am) y al ser gratuito el aparcamiento, dejan sus vehículos hasta el final de sus labores como se aprecia en la figura 07.

Estos resultados para la variable de aparcamientos revieron significativa importancia ya que se entiende la motivación de la búsqueda de estacionamientos y el tiempo en el que permanecen en ellos. Adicionalmente de las entrevistas realizadas a los conductores para conocer las razones por las que estacionan sus vehículos en espacios prohibidos y debidamente señalizados, los entrevistados refieren desconocer la legitimidad de las autoridades municipales, atribuyendo con mayor importancia las motivaciones de su desplazamiento; "el municipio no me dará de comer", "sé que está probibido, pero tengo que trabajar"o "el sistema de trasporte público es muy lento" son las respuestas más comunes. Pese a la democratización de elecciones de autoridades y la supuesta democracia que se viven en el país y la ciudad, dichas afirmaciones, reflejan la realidad cultural que vive la ciudad como sociedad que no solo se observa en estas variables, sino que también se transmutan en muchos de los problemas que sufre la ciudad como el autoconstrucción, la informalidad y la ocupación del territorio de espacios no autorizados y ubicados en zonas de alto peligro. 


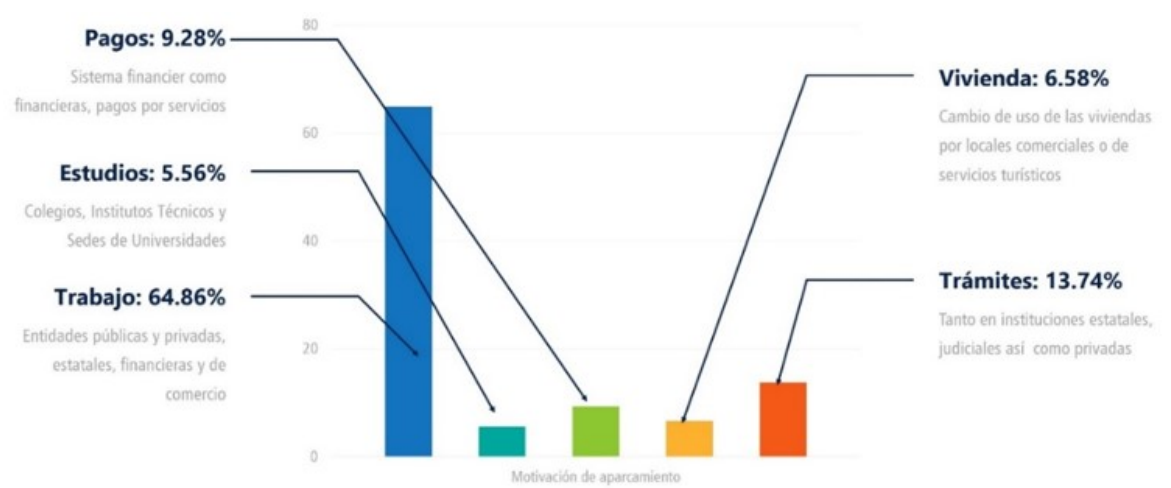

FIGURA 10

Motivación de aparcamiento en el centro histórico de Cusco. Fuente: Elaboración Propia.

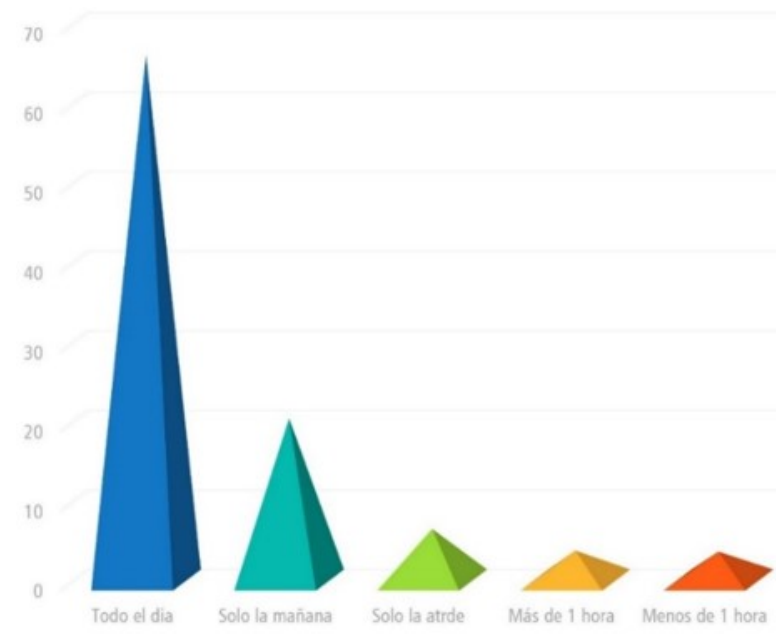

FIGURA 11

Tiempo de ocupación de los espacios de estacionamientos. Fuente : elaboración propia.

2. Tráfico vehicular

1. Como se afirmó en la introducción del estudio, existen estudios de tráfico del centro histórico realizados por la Municipalidad Provincial del Cusco, sin embargo, los datos encontrados solo reflejan el número de vehículos que concurren al centro histórico, y no se posee data referida a los tiempos de retraso que ocurren en las intersecciones de las vías por las que estamos convencidos son indicadores que reflejan de mejor manera el nivel de tráfico vehicular, como se precia en la figura 08.

Si bien es cierto los resultados reflejan una diversidad de tiempos de demora en las intersecciones, en cada una de ellas se supera los tiempos óptimos esperados para la sección de la vía y su dirección; sin embargo si analizamos las calles con mayor congestión y las relacionamos con la ubicación de los polos de atracción ubicados en el Centro Histórico, tenemos como resultado que a mayor cercanía del polo, mayor es el tráfico vehicular; es decir que la ubicación y rubro del polo de atracción, determina el grado de tráfico vehicular.

Así la Avenida Pardo que se ubica a una cuadra de los bancos y entidades financieras más concurridas, la calle matara distanciada a una cuadra de las entidades públicas más sobresalientes como el Palacio de Justicia y el Municipio Provincial del Cusco, así como la plaza San Francisco que de igual forma se ubica a una cuadra de las instalaciones de la Empresa Prestadora de Servicios 
de agua y alcantarillado SEDA CUSCO, la propia Municipalidad Provincial de Cusco, son los que registran la mayor cantidad de tiempo en demoras de tráfico vehicular.

Además, del inventario levantado en el estudio sobre la capacidad de estacionamientos existentes, tantos autorizados como los prohibidos que sin embargo los ocupan diariamente, se puede apreciar que el mayor nivel de tráfico se ubica en las calles donde existe mayor cantidad de espacios de estacionamiento, siendo éstos la calle Tullumayo con más de 40 espacios en la vía pública además de contar con 02 playas de espaciamientos privados y de igual forma se precia en la calle Saphy que presentan menos de 14 segundos de tráfico con más de 45 espacios de estacionamientos.

Todas estas calles se ubican en el casco monumental y principalmente a menos de cuatro cuadras de la Plaza de Armas de Cusco, que al igual de los polos de atracción que también se ubican a las mismas distancias. Cabe resaltar que dichas ubicaciones no se encuentran distribuidas a lo largo del casco monumental, sino que se concentran en cuatro sectores del centro histórico, así las vías troncales como la Avenida el Sol, donde se enclavan las principales entidades financieras, la Plaza San Francisco a dos cuadras de la Plaza de Armas, la calle Matará localizada a una cuadra de la Avenida El Sol y la calle Saphy donde se concentran la mayor cantidad de agencias y oficinas prestadoras de servicios turísticos.

Esto remarca que la ubicación de los polos de atracción se relaciona directamente con las calles de mayor tráfico vehicular analizada de manera gráfica como en la figura 09 mediante la superposición de datos y su interpretación categórica.

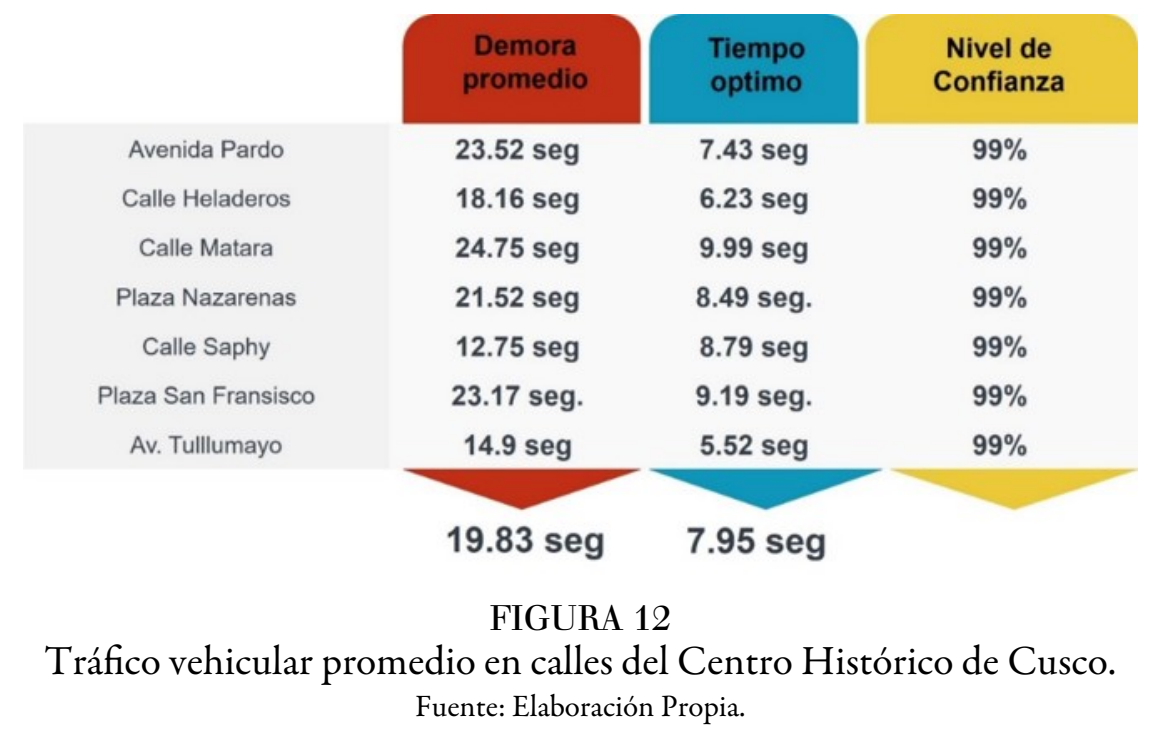

3. Relación del déficit de estacionamientos y el tráfico vehicular.

1. 


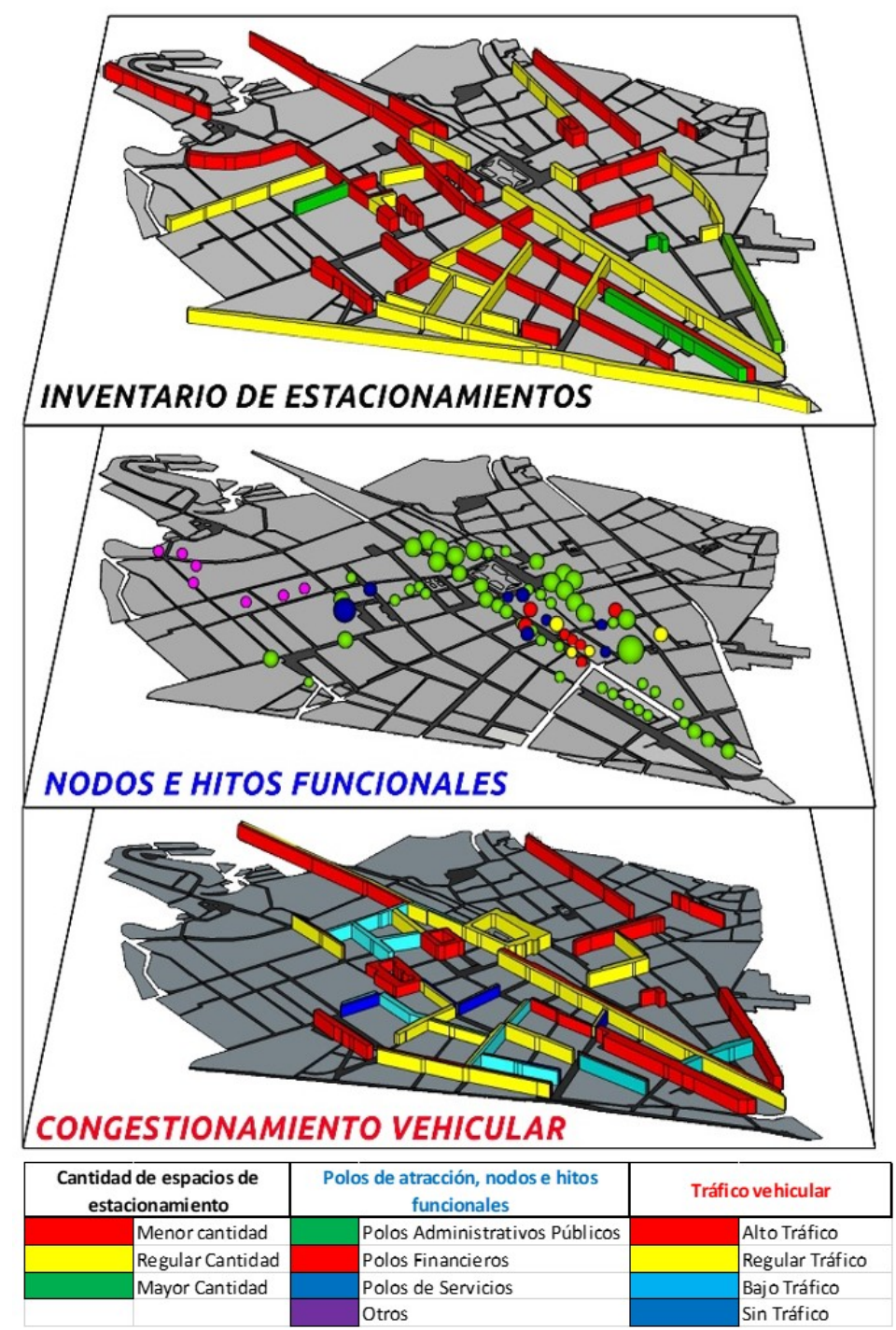

FIGURA 13

Impacto del déficit de estacionamientos en el tráfico vehicular. Fuente: elaboración propia.

\section{Análisis estadístico de correlaciones}

Para verificar la hipótesis Hi: El tráfico vehicular se asocia a la cantidad de vehículos estacionados en la ciudad de Cusco en el 2020, el nivel de significancia establecido fue de $\alpha=5 \%$ (0.05), con un nivel de confianza al 95\%. Aplicando la prueba estadística $r$ de Pearson, por tratarse de variables cuantitativas continuas, obteniendo los siguientes resultados. 
TABLA 5

. Resultados de correlación entre la demora en el tráfico y los vehículos estacionados en las zonas de estudio.

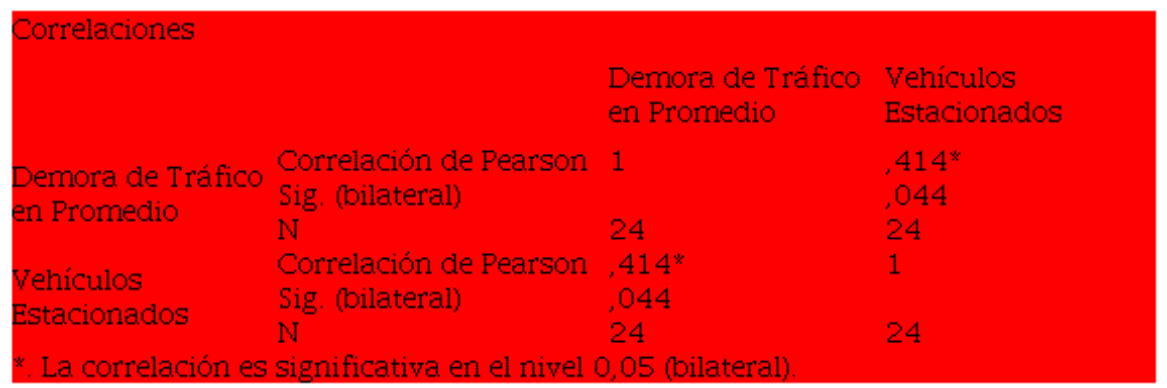

Fuente; elaboración propia.

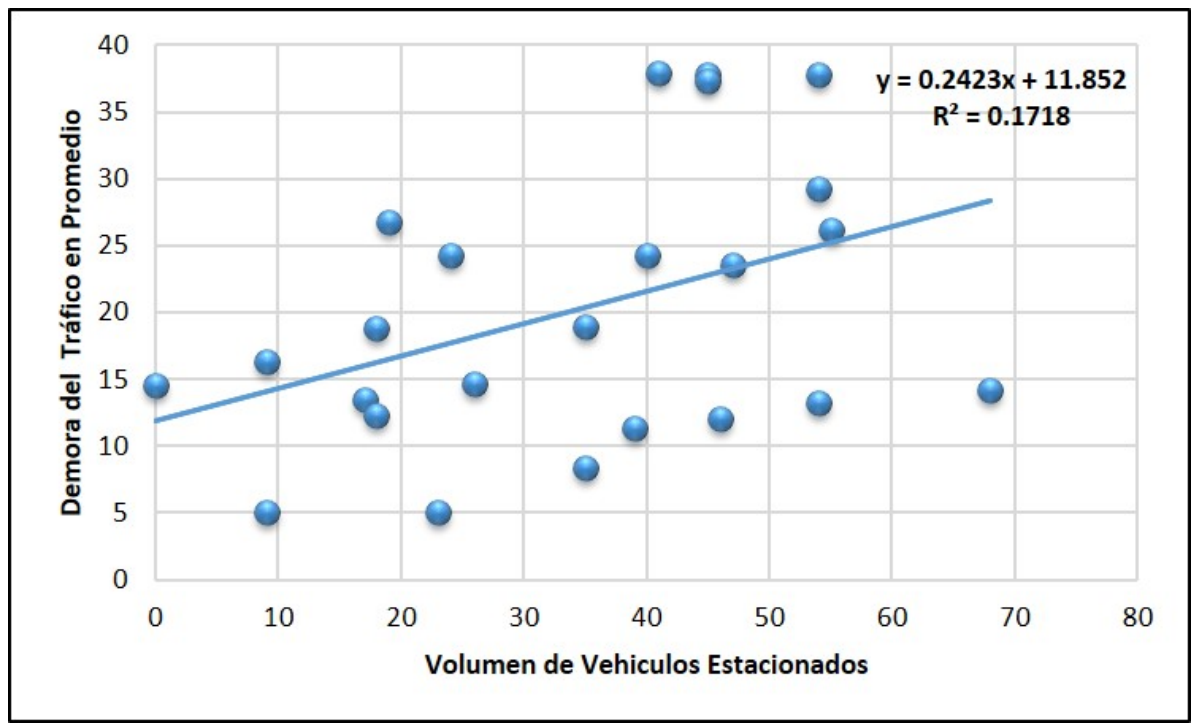

FIGURA 14

Diagrama de dispersión entre la demora en el tráfico y los vehículos estacionados en las zonas de estudio. Fuente: elaboración propia.

En la Tabla 5, se muestran los resultados del estadístico de prueba $\mathrm{r}$ de Pearson entre los vehículos estacionados y la demora del tráfico en promedio, donde se logra constatar una correlación positiva entre las variables $(\mathrm{r}=0.414)$, y un $\mathrm{p}$ valor $=0.000$ que por ser menor al nivel de significancia establecido en la investigación $(\mathrm{p}<0.05)$, permite rechazar la hipótesis nula $(\mathrm{H} 0)$, y aceptar la hipótesis planteada $(\mathrm{Hi})$, concluyendo que: "El tráfico vehicular se asocia a la cantidad de vehículos estacionados en el Centro Histórico de Cusco al 2020".

Es decir, a medida que aumenta la cantidad de vehículos estacionados en las avenidas y calles que convergen en dicho centro histórico, se espera un mayor tráfico en los vehículos circundantes, hecho que se precisa con mayor claridad en la Figura 10, donde se observa una relación lineal entre las variables, y se sostiene que el $17.18 \%(\mathrm{R} 2=0.1718)$ del nivel de tráfico se explica por el volumen de vehículos estacionados en la zona, en este particular se puede proyectar el promedio de demora en el tráfico al considerar la cantidad de vehículos estacionados en la zona como un factor predominante $(y=0.2423 x+11.852)$, cabe destacar que para ello se deben tomar en cuenta otros factores, como la amplitud de las calles y avenidas, la cultura de los conductores, entre otras. 


\section{REFERENCIAS}

Arce, D. (2008). Factibilidad técnico Económico de la Construcción de Estacionamientos subterráneos para la Vega Central. Universidad de Chile.

Arzaluz, S. (2005). La utilización del estudio de caso en el análisis local. Región y sociedad. 17 (32) 111-144. http:// www.scielo.org.mx/pdf/regsoc/v17n32/v17n32a4.pdf

Barrientos, M. (2010). Jurisprudencia por daños en estacionamiento de vehiculos regido por la "Ley del consumidor". Derecho .

Benévolo, L. (1999). Historia de la arquitectura moderna. Gustavo GILI.

Benitez, V. (2017). Estacionamiento público y su accesibilidad al comercio del centro histórico de la ciudad de Toluca. Universidad Autónoma del Estado de México.

Bull, A. (2003). Congestión de tránsito: el problema y cómo enfrentarlo. United Nations Publications.

Bull, A., \& Thomson, I. (2002). La congestión del tránsito urbano: causas y consecuencias económicasy sociales. División de Recursos Naturales e Infraestructura Unidad de Transporte. https://repositorio.cepal.org/bitstream/handl e/11362/6381/1/S01060513_es.pdf

Burriel de Orueta, E. (2009). La planificación territorial en la comunidad Valenciana (1986-2009). Departamento de geografía-Universidad de Valencia.

Carranza Casana, N. \& et. al (2017). Propuesta de solución para el déficit de estacionamiento vehicular, caso de estudio la zona del nuevo centro empresarial del distrito de Magdalena del Mar, provincia y departamento de Lima . Resumen Ejecutivo. Universidad Peruana de Ciencias Aplicadas (UPC).

Castillo, L., \& Alonzo, D. (2018). Evaluación de los estacionamientos subterráneos en Rivera Navarrete. [Tesis de grado, Licenciatura Ingeniero Civil ]. http://tesis.pucp.edu.pe/repositorio/bitstream/handle/20.500.12404/11731/ DIEGO\%20ALONZO\%20LUCANO\%20CASTILLO_EVALUACI\%c3\%93N\%20DE\%20LOS\%20ESTA CIONAMIENTOS\%20SUBTERR\%c3\%81NEOS\%20EN\%20RIVERA\%20NAVARRETE.pdf?sequence= 1\&isAllowed=y

Chávez, D. (2015). Estudio de factibilidad para la creación de un parqueadero público en la zona céntrica de la ciudad de Milagro. Universidad estatal de Milagro.

Chávez, D. G., \& Arangudi, A. (2015). Estudio de factibilidad para la creación de un parqueadero público en la zona céntrica de la ciudad de Milagro. Universidad Estatal de Milagro.

Choay, F. (1983). El urbanismo; utopias y realidades. Lumen.

Coba Sandoval, O. P. (15 de Noviembre de 2013). Estudio de factibilidad para la creación de un parqueadero automatizado en la ciudad de Ibarra con horario continuo. [Tesis de grado, Ingeniero en Contabilidad y Auditoría]. http://repositorio.utn.edu.ec/handle/123456789/2958

Cordero, M. S. (2012). Los vehículos motorizados privados y el problema del transporte público en los centros históricos: el caso de Cuenca Ecuador. Estoa, 1 (1) , 73-93. 
Cossio, C. (1986). Estudio de la problemática de estacionamiento en el centro de Tampico, y propuestas de solución. Universidad autónoma de Nuevo Leon.

Coulomb, R. (2008). Sustentabilidad de la centralidad urbana e histórica. Una reflexión desde el centro histórico de la ciudad de México. Quivera.

Cumbre Pueblos. (27 de mayo de 2018). Contaminación ambiental: Qué es, tipos de contaminación, causas, consecuencias y soluciones. https://cumbrepuebloscop20.org/medio-ambiente/contaminacion/ambiental/?cn -reloaded $=1$

Curz Alarcón, C. A. (Julio de 2013). Proyecto de factibilidad para la creación público en el sector centro de la ciudad de Quito. [Tesis de especialización en Administración de empresas, Ingeniero comercial ]. https://dspace.ups.edu .ec/handle/123456789/5207

Dueri, P. (2017). Teoría arquitectura y urbanismo. Dossier MMXVI. https://issuu.com/patriciadueri/docs/teoria_a rq_y_urba_2016

Duque Escobar, G. (3 de Marzo de 2018). El enorme reto de limpiar 'el río más contaminado del mundo' en Indonesia. El Espectador: medio ambiente. http://smpmanizales.blogspot.pe/2018/03/el-enorme-reto-de-limpiar-el-riomas.html

Encalada, F. (2015). Investigación de la oferta y demanda de estacionamientos para la propuesta de soluciones a la congestión vehícular en el centro de la ciudad de Riobamba. Universidad Nacional de Chimborazo.

Encinas Alagon, M. (2011). El sistema medio ambiente. Principios básicos. M. D. Encinas Malagón

Enriquez, D. (2009). Estudio de Factibilidad de un estacionamiento vehicular con un sistema de elevación. Universidad de Guayaquil.

Escobar, O. (2015). La ordenanza que establece y regula el sistema municipal de estacionamiento rotativo en la vía pública y el tránsito vehicular en el centro de la ciudad de Ambato. Nueva dely.

Espinoza, F. (2009). Plan de negocio para la implementación de estacionamientos verticales en la ciudad de Arequipa. Universidad Esan.

Europa Press. (4 de Enero de 2012). El ayuntamiento detecta un déficit de 41.250 aparcamientos y plantea estacionamientos al borde de la ciudad. La Vanguardia.

Ferrer, A. (1973). Parkings en el centro histórico de Barcelona. Gatcpac II.

García, A. (2016). Aparcamientos y humanización en el centro histórico de Lugo. Universidad de Coruña.

Garnica, R. (2004). Riesgos por inundación asociados a eventos de precipitación extraordinaria en el curso bajo del río Tecolutla, Veracruz. Investigaciones geograficas, (55).

Gehl, J., \& Gemzoe, L. (2002). Nuevos espacios urbanos. Gustavo Gil.

Gonzales, G., \& et. al. (2014). Contaminación ambiental, variabilidad climática y cambio climático: Una revisión del impacto en la salud de la población peruana. Revista peruana de medicina y salud pública, 31 (3). http://www.sc ielo.org.pe/scielo.php?script $=$ sci_arttext\&pid=S1726-46342014000300021

Guerra, L. (2014). Elogio de la Ciudad. Semblanza de la filosofía como fenómeno urbano. Thémata: revista de filosofía , (51) 145-167.

Gutierrez, J. (1995). Movilidad, Medio ambiente y Patrimonio histórico-artístico en ciudades históricas. Universidad

Complutense de Madrid. 
Harth-Terré. (2006). Filosofía en el urbanismo. Tierra y Arte.

Huamanciza, D. (2016). Dirección del proyecto: implementación de playa de estacionamiento automática en San Isidro. Universidad Peruanas de Ciencias Aplicadas (UPC).

Linauer, M., \& Leihs, D. (2003). Generating floating car data by using gsm-network. Proceedings of the 10th World Congres and Exibition on Intelligent Trsanport Sustems and Services.

Maya, E. (2014). Métodos y técnicas de investigación. Universidad Nacional Autónoma de México.

Ministerio de Transportes y Comunicaciones. (2017). Cusco: Tráfico vehicular total, según tipo de vehiculo y unidades de peaje. Ministerio de Transportes y Comunicaciones.

Molano, F. (2016). El derecho a la ciudad: de Henri Lefebvre a los análisis sobre la ciudad capitalista contemporánea. Folios. Segunda epoca, (44) 3-19.

Montaño, G., \& Sempèrtegui, J. (2017). Implementación del servicio municipal de estacionamiento tarifado en la ciudad de Zamora (SMET-Z) y su impacto en la Movilidad urbana: periodo de estudio mayo-agosto del 2016. [Tesis de grado, Ingeniería en Administración Pública]. Universidad Nacional de Loja.

Montoya, M., \& Mesa, S. (2016). Estudio de factibilidad para la administración de zonas de estacionamiento regulado. Universidad EAFIT.

Morán Proaño, M, \& Álvarez Rodríguez, O. (2012). Investigación de las vibraciones por tráfico en las construcciones patrimoniales de adobe. Revista de la construcción, 11(2), 39-53. https://dx.doi.org/10.4067/S0718-915X2012 000200005

Noriega Perez, L. (2017). Cambios en los mecanismos de búsqueda de estacionamientos en el distrito de Miraflores, mediante la innovación tecnológica, a través del nuevo modelo de economía compartida del siglo XXI. Universidad Pontificia de Ciencias Aplicadas.

Pareja, 0. (26 de Marzo de 2016). Número de parqueos insuficientes en Centro Histórico. Diario Correo.

Pedraza, L. \& et. al. (2012). Control de tráfico vehicular usando ANFIS. Ingeniare. Revista chilena de ingeniería, 20(1), 79-88. https://dx.doi.org/10.4067/S0718-33052012000100008

Pérez, F. \& et. al. (2011). Análisis del flujo del tráfico vehicular a través de un modelo macroscópico. DYNA.

Ramírez, P. (2011). Espacio público y ciudadania en la ciudad de México. Percepciones, aporpiaciones y prácticas sociales en Coyoacán y su Centro Histórico. Municipal de Michuacan.

Rampoldi Aguilar, R. (2009). Habitabilidad y calidad de vida en tres barrios del límite ubano- rural de Mar de Plata. Hologramática 1 (10).

Robles, D., Naañez, P., \& Quijano, N. (2009). Control y simulación de tráfico urbano en Colombia: Estado del arte. Revista De Ingeniería, 0 (29), 59-69. doi:10.16924/riua.v0i29.245

RPP noticias. (17 de Noviembre de 2012). Cusco: Inician proyecto para recuperar contaminado río Huatanay. RPP. RPP noticias. https://rpp.pe/peru/actualidad/cusco-inician-proyecto-para-recuperar-contaminado-riohuatanay-noticia-541236\#: :text=Cusco\%3A\%20Inician\%20proyecto\%20para\%20recuperar \%20contaminado\%20r\%C3\%ADo\%20Huatanay,-El\%20gobierno\%20regional\&text=Este\%20r\%C3\%ADo \%20se\%20ha\%20convertido,cruza\%20la\%20ciudad\%20del\%20Cusco

Serradell, M. J. (1965). Urbanismo y filosofía. Cuadernos de arquitectura, (59) 11. https://www.raco.cat/index.php/ CuadernosArquitectura/article/view/110516

Sola, M. (2016). Las formas de crecimiento urbano. Universidad Politécnica de Cataluya.

Solis, A. ( Junio de 2014). Antiguamente el río Huatanay ha sido utilizado para el cultivo. Diario "La República".

Suarez, A. (2004). El Centro Histórico de la ciudad de México al inicio del siglo XXI. Revista INVI, 19 (51) 75-95.

Thomsom, I., \& Bull, A. (2001). La congestión del tráfico urbano: causas y consecuencias económicas y sociales. División de Recursos Naturales e Infraestructura.

Vega, A., \& Bustillos, J. (2010). Movilidadpeatonal en cehtros históricos de ciudades pequeñas. Universidad de Cantabria.

Vicente, M. (1983). Análisis y solución del problema de estacionamientos en el centro de las ciudades. Consejo Superior de Investigación de España. 
Vicente, M. (2010). Análisis y solución del problema de estacionamiento en el centro de las ciudades. Consejo Superior de Investigaciones Científicas.

Wardrop, J. G.; Whitehead, J. I. (1952). Correspondence. Some Theoretical Aspects of Road Traffic Research. ICE Proceedings: Engineering Divisions 1 (5) 767. https://doi.org/10.1680/ipeds.1952.11362

\section{Notas}

* Arquitecto de profesión, con estudios de Post Grado en la Universidad de San Antonio Abad de Cusco, consultor proyectista de gobiernos locales y regionales, docente e investigador de la Escuela Profesional de Arquitectura de la Universidad Andina de Cusco registrado en la base de datos de CONCYTEC Perú, ganador de concursos de financiamiento de proyectos de investigación, expositor en congresos de investigación nacional e internaciones.

** Arquitecto de profesión, con estudios de Post Grado en "ordenación y Gestión del desarrollo Terirotrial y Local” en la Universidad de Sevilla - España, estudios de Posgrado en Asentamientos Humanos en la Universidad Nacional de Ingeniería Lima-Perú, Master Erasmus Mundus “Estudios Urbanos en Regiones Mediterráneas” en la Universidad de Sevilla y Universidad Técnica de Lisboa.Docente Universitario tiempo completo- Universidad Andina de Cusco-Perú 